\title{
Uma comunidade desportiva e as redes de cooperação entre organizações promotoras de desporto
}

http://dx.doi.org/10.11606/1807-5509201800040621

\author{
João António GARCIA* \\ José Manuel Leal SARAGOÇA* \\ Mário Rui Coelho TEIXEIRA** \\ ${ }^{*}$ Centro Interdisciplinar \\ de Ciências Sociais, \\ Universidade de Évora \\ Évora, Portugal. \\ **Departamento de \\ Desporto e Saúde, \\ Universidade de Évora, \\ Évora, Portugal.
}

\section{Resumo}

É fundamental o estudo das organizações desportivas, enquanto entidades sociais essenciais no processo de desenvolvimento do desporto em Portugal, uma vez que as relações interorganizacionais são determinantes para a sustentabilidade e competitividade no setor desportivo. 0 estudo tem como objetivo identificar e compreender as relações de cooperação que as instituições promotoras de desporto do concelho de Évora estabelecem entre si, como forma de potenciar a eficiência coletiva. A investigação enquadra-se nos estudos de carácter exploratório e assume a configuração de um estudo de caso. A ferramenta utilizada no tratamento dos dados foi a Análise de Redes Sociais (ARS), tendo os dados sido recolhidos através de questionário sociométrico e complementados com análise documental. Concluiu-se que, na generalidade, as dinâmicas de cooperação em rede são fracas, encontrando-se algumas exceções ao nivel dos subgrupos. Perante os números de praticantes e modalidades disponibilizadas, aferiu-se que as organizações desportivas desenvolvem, através das suas estruturas, uma função interventiva na comunidade. A Câmara Municipal de Évora é a instituição que apresenta maior centralidade nas diferentes redes. A perspetiva dos atores em rede é exclusivamente centrada em interesses particulares, sendo que, as relações de cooperação acontecem essencialmente para troca de informação. A prospetiva de cooperação futura apresenta múltiplas potencialidades, o que, certamente, contribuirá para o desenvolvimento desportivo do concelho.

Palavras-Chave: Atividade Física e Comunidade; Setores Desportivos; Análise de Redes Sociais; Parcerias.

\section{Introdução}

Um dos grandes desafios da gestão desportiva contemporânea é entender que o desporto tem necessidade de constante estudo e interpretação. As complexas alterações que ocorrem no seu ambiente exigem a formulação de estratégias para o desenvolvimento do desporto ${ }^{1-2}$. Da mesma forma, o desporto nacional e, em especial, a atividade desportiva desenvolvida nas regióes com mais assimetrias populacionais, devem ser sistematicamente estudados e avaliados.

Neste contexto, o estudo das organizações enquanto entidades sociais de desenvolvimento humano e como agentes essenciais para o cumprimento do processo de desenvolvimento do desporto nacional, permite assegurar e atender às necessidades específicas das populaçóes, aspeto fundamental na construção de uma matriz de atuação que maximize os recursos existentes ${ }^{3}$.

A crescente robustez epistemológica e metodológica dos estudos de Análise de Redes Sociais (Social Network Analysis) tem melhorado muito nos últimos anos. De facto, os progressos registados na análise e caracterização dos recentes sistemas sociais, enfatizam a utilização desta metodologia, que permite observar e representar as ligações entre grupos, organizações e indivíduos que cooperem ${ }^{4}$. $\mathrm{O}$ estudo das redes de cooperação é, assim, um processo multidisciplinar que engloba diferentes dimensóes, contextos e atividades produzidos em sociedade ${ }^{5-6}$.

Atualmente, as políticas sociais tendem para uma descentralização dos serviços comunitários em geral e, em particular, das organizaçóes sem fins lucrativos ${ }^{7}$, 
sendo o espaço de intervenção divergente na missão e convergente nas influências recíprocas que exercem uns sobre os outros ${ }^{8}$. Ou seja, o ambiente observado em rede, na qual as organizações se inserem, é influenciado e também exerce influência, revelando uma complexidade de dependência mútua entre as organizaçôes, os indivíduos e o ambiente, motivos pelos quais as redes se apresentam como uma opção para comunicação e partilha de bens e serviços e das expetativas dos indivíduos que nela interagem?

Numa abordagem às organizaçóes desportivas, importa antecipadamente contextualizar o papel e o posicionamento destas no seio do sistema desportivo. Foi desenvolvido o "modelo dos três sectores desportivos", a partir do qual foram qualificadas as organizaçóes desportivas por setor público, setor privado e setor profissional. Sendo o seu funcionamento cada vez mais exercido no quadro de parcerias, ou seja, o setor público é fundamental no financiamento ao setor não lucrativo, que, por sua vez, promove a prática desportiva na comunidade ${ }^{8}$.

O setor público abrange as organizaçóes de natureza relacionada com o Estado, ao nível nacional ou regional, que têm como principal objetivo o desenvolvimento do desporto, através de projetos para os setores do associativismo e profissional e apoios nas áreas da formação de agentes especializados, da legislação e da ética desportiva, entre outras ${ }^{8}$.

O setor não lucrativo associativo, também conhecido pela prática de voluntariado, é formado por clubes e associaçóes oriundas das comunidades locais, que facilitam a prática do desporto a diferentes níveis e organizam e gerem eventos desportivos ${ }^{8}$.

Ao setor profissional pertencem as ligas profissionais e os seus associados. Neste domínio, também atuam as organizaçóes empresariais, que não sendo instituições desportivas, influenciam fortemente o mercado desportivo, na medida que prestam serviços em alguns setores fundamentais ao desporto ${ }^{8}$.

O estudo realizado em 2014 por Evans et al. ${ }^{10}$ destaca o desconhecimento da missão que cada uma das organizaçôes locais tem sobre os seus parceiros, descoordenação que influencia negativamente a capacidade dos modelos de gestáo para responderem e se adaptarem aos problemas e necessidades das comunidades locais.

Aferir a funçáo do desporto no desenvolvimento humano e social tem sido, também, um dos grandes desafios da gestão desportiva. As políticas desportivas de investimento público têm exigido, de forma crescente, que o desporto se propague para áreas de interesse público e de promoção de saúde e bem-estar social ${ }^{11}$. Todavia, são necessários mais estudos que comprovem a capacidade do desporto no desenvolvimento de competências na comunidade, nomeadamente a coesão social, o diálogo, a inclusão, a participação e muitos outros valores fundamentais à vida comunitária ${ }^{10,11}$.

O desenvolvimento e o sucesso social do desporto parecem depender cada vez mais das parcerias, do partenariado e do envolvimento coletivo, o que exige ultrapassar vários e tradicionais obstáculos. De facto, como bem lembra EDWARDs ${ }^{11}$, quando os indivíduos são parte integrante das açóes, é gerado um estado de empatia geral que, certamente, vai traduzir-se em vinculação e pró-atividade coletiva, expressando, assim, a cultura de aprendizagem e os valores individuais e coletivos da comunidade. Porém, diz o autor, quando é apresentado um evento à comunidade verifica-se frequentemente a existência de alguma desconfiança da validade da iniciativa. Este é, na verdade, um obstáculo recorrente das relaçôes cooperativas entre os atores.

Por conseguinte, afigura-se de todo pertinente estudarmos a capacidade que as organizaçóes desportivas apresentam para manterem uma estrutura de relacionamentos de cooperação, principalmente quando se observa uma redução dos orçamentos e dos incentivos atribuídos às organizações desportivas, através das políticas governamentais. É ainda importante salientar o facto de as organizaçóes desportivas competirem entre si pelos financiamentos provenientes do Estado, o que implica, na maioria dos casos, que as organizaçóes do setor não lucrativo abdiquem de desenvolver as atividades para o qual estão destinadas, que é, como também já referimos anteriormente, um papel de intervenção social ${ }^{7,11,12}$.

Neste contexto, é importante perceber as características das organizaçóes e entender as estratégias assumidas, os jogos de poder, a influência e a dependência dos relacionamentos interorganizacionais, isto é, importa compreender como se caracteriza a estrutura dos relacionamentos entre os atores e a forma como influenciam a dimensáo de aprendizagem coletiva que, consequentemente, vai permitir aferir as motivaçóes particulares para a participação em rede r $^{7,12}$.

As relações interorganizacionais, no campo de intervenção das organizações desportivas, são determinantes para a sustentabilidade e 
competitividade no setor ${ }^{13}$. Estas enquadramse numa área de especialização em permanente desenvolvimento e, principalmente, em constante alteração, factos que remetem para a necessidade de contratarem profissionais qualificados e bem informados. A este facto alia-se a necessidade das organizaçóes terem acesso ao capital social proveniente da cooperação em rede, nomeadamente o acesso a novas tecnologias, a técnicas, a "segredos de profissão", a projetos e informação especializada, que constituem fatores facilitadores de rápida adaptação e que resultam do incremento de vantagens para o grupo, relativamente à concorrência externa ${ }^{11,14,15}$.

É crescente e consensual a importância do estudo e análise das redes de cooperação no campo do conhecimento das sociedades e organizaçóes, onde se constrói o fenómeno das redes interorganizacionais ${ }^{16-18}$. Um dos focos observados nesta área de estudo é o facto da cooperaçáo facilitar e promover os processos no interior e exterior das organizações e amplificar sinergias de partilha de informaçáo e recursos fundamentais para que se alcance competitividade e, consequentemente, os objetivos individuais e coletivos a que se propóem ${ }^{9,16,17,19,20}$.

As estratégias conjuntas refletem a necessidade que as organizaçóes têm em promover relaçóes cooperativas, por forma a se protegerem e defenderem de ameaças externas ${ }^{18,20-21}$, sendo que, para a formaçáo de redes de cooperação não basta juntar as organizaçóes de acordo com a sua proximidade geográfica. A condição basilar é a existência de objetivos comuns, interaçóes, uma gestấo coordenada e ambiente saudável vivido em rede ${ }^{21}$.

A confiança é, sem dúvida, um fator determinante da qualidade dos relacionamentos em rede. Este aspeto tem sido amplamente estudado estando presente nas relaçóes sociais de forma universal. Vários autores consideram a confiança como um dos principais elementos na formação e evolução de uma rede, já que, através da sua construção ficam facilitadas as relaçóes e, consequentemente, aumentam os fluxos de cooperação entre os atores. FIALHO ${ }^{15}$ acrescenta ainda que "confiança" é a premissa fulcral nos relacionamentos interorganizacionais ${ }^{14}$.

As relaçóes ocorridas em ambiente de confiança reforçam os laços estabelecidos e facilitam a colaboração entre organizaçôes ${ }^{22,23}$. Por outro lado, este elemento está associado ao espoletar de comportamentos cooperativos, a níveis de relacionamentos mais intensos e, consequentemente, ficam reunidas as condiçóes primárias para alcançar o sucesso coletivo ${ }^{22}$.

As estruturas sociais apresentam padrôes de envolvimento, os quais podem ser estudados com a Análise de Redes Sociais (ARS) e medidos através de indicadores relacionais, que explicam os vínculos existentes entre os indivíduos em "rede" 24 . As características, como a densidade, o nível de intermediação, a coesão, o poder, a posição social e o prestígio podem ser objetivadas em termos relacionais, já que estes elementos permitem que observemos as particularidades dos contactos entre os vários atores ${ }^{25,26}$.

Alguns estudos desenvolvidos no quadro da ARS abordam as relaçóes comunitárias. No estudo realizado em 2015, Maya-Jariego e Holgado ${ }^{24}$ reconhecem a contribuição inovadora de pesquisas no âmbito de ARS, aplicados na comunidade, uma vez que permitem a sua aplicabilidade em diversos contextos e domínios, possibilitando a compreensão dos relacionamentos entre pessoas, grupos ou organizaçóes. Sendo esta uma ferramenta de intervenção, a análise e tratamento de dados permite inferir padróes colaborativos, que intuitivamente podem não ser visíveis, e observar influências mútuas entre organizaçóes.

O estudo realizado orientou-se no sentido de caracterizar e representar a rede de relaçóes de cooperação entre as Entidades e organizaçóes desportivas sem fins lucrativos, do concelho de Évora. Assim, formulou-se a questão de partida: Como se caracterizam as relaçôes de cooperação entre as organizaçóes desportivas sem fins lucrativos, do concelho de Évora? Em conformidade, enunciaramse como principais objetivos para a investigação, os seguintes:

- Representar a rede das entidades e organizaçóes desportivas sem fins lucrativos no concelho de Évora;

- Identificar as interaçóes subsequentes ao posicionamento dos atores na rede;

- Conhecer as dinâmicas de cooperação que sustentam os relacionamentos interorganizacionais das instituiçóes promotoras do desporto;

- Identificar os efeitos da rede no comportamento das organizaçóes desportivas;

- Identificar a intençáo futura de relacionamentos entre as organizaçóes desportivas do concelho de Évora. 


\section{Método}

Esta investigação enquadra-se nos estudos de carácter exploratório, tendo sido utilizada uma metodologia qualitativa e por ser um tipo de pesquisa muito particular, assume a configuração de um estudo de caso ${ }^{27,28}$.

Os dados foram recolhidos através do questionário sociométrico, complementados pela análise documental e tratados com o software UCINET 6.5.

Com a finalidade de recuperar informação existente sobre a temática em estudo, foi realizada uma pesquisa às bases referenciais da B-on - Academic Search Complete; Elsevier; Eric; Springer; Taylor \& Francis; Web of Science; Wiley; na revista Redes: revista hispana para el análisis de redes sociales; no Repositório Cientifico de Acesso Aberto em Portugal. $\mathrm{O}$ mapeamento às bases de dados com as palavras-chave: social network analysis and sports organizations; cooperation and netwoork and sports, não devolveu nenhum resultado específico, razão pela qual podemos afirmar que as organizaçóes desportivas são pouco estudadas, relativamente à sua eficiência coletiva na comunidade.

Na parte inicial do estudo pretendeu-se caracterizar as entidades e organizaçóes desportivas, relativamente à natureza das atividades disponibilizadas, ao intervalo das idades e ao número total de praticantes por sexo. Por último, foi conhecido o modelo de financiamento das organizaçôes pertencentes à amostra.

O principal foco do estudo foi avaliar a rede de relacionamentos formais e informais; a rede de partilha de recursos (recursos materiais, recursos físicos, recursos humanos e recursos financeiros); a rede de "quem" é mais importante para o desenvolvimento desportivo do concelho de Évora; e a rede de intenção de contactos futuros.

Para todas as redes (exceto a rede de desenvolvimento desportivo) foram aplicadas as seguintes medidas descritivas: densidade, centralidade (inDegree e outDegree), nível de intermediação e cliques.

A delimitação do estudo assentou em três aspectos: (1) seleção das entidades desportivas, das associaçóes promotoras de desporto, dos clubes de praticantes e clubes desportivos; com base no mapeamento

\section{Resultados e Discussão}

A FIGURA 1 apresenta a percentagem das instituiçóes desportivas pertencentes à amostra, agrupadas pelo número de praticantes. realizado às organizaçóes desportivas que constavam na página da Câmara Municipal de Évora (CME), dedicada ao associativismo local; (2) localização geográfica das instituiçóes selecionadas, incluindo-se as que pertenciam ao concelho de Évora; (3) o estado operacional - instituiçóes em atividade.

Posteriormente foram estabelecidos contactos telefónicos com todas as instituiçóes, apresentando o estudo e colocando as questóes-chave: (a) No presente momento a sua organização tem alguma atividade desportiva a decorrer? (b) Encontra-se disponível para colaborar com a presente investigaçáo, através do preenchimento de questionário?

A amostra final foi composta por uma Entidade pública, uma associação académica, seis associações desportivas e 49 outras instituiçóes, entre clubes de modalidades federadas e organizaçóes desportivas promotoras de desporto, totalizando 57 organizaçóes.

Foram contactados todos os gestores desportivos, ou pessoas que exercem funçóes similares, a quem foram entregues os questionários e elucidados acerca dos procedimentos a serem tidos em conta na resposta às questóes, pretendendo-se que o preenchimento do questionário fosse efetuado com a colaboração de outros membros da organizaçáo. Todos os participantes foram informados da confidencialidade e anonimato das respostas, procedimentos que asseguram a confiabilidade e descartam a possibilidade de distorçóes percetivas individuais.

No processo de conceção e realização dos questionários foram consideradas as linhas orientadoras, que a comunidade científica estabelece como critérios a seguir aquando da elaboração deste género de documentos, os quais correspondem à natureza das questôes, das escalas a utilizar, da aplicação do préteste, da validade do questionário e do tratamento dos dados ${ }^{17,27-29}$. A partir do pré-teste verificou-se a necessidade de que o questionário fosse elaborado com a lista integral de todas as instituiçóes participantes. No sentido de simplificar a representação das instituiçôes, foram substituídas as suas designaçôes pela abreviatura ID, acrescida de um número de ordem.

Das instituições em estudo destacam-se os seguintes resultados: $37 \%$ até 50 praticantes, $28 \%$ entre 51 e 99, 16\% situam-se no intervalo entre 101 
e 199, enquanto $19 \%$ das instituiçóes detêm nas suas estruturas mais de 200 praticantes. Do último valor percentual apresentado, importa salientar que é constituído pela Entidade que representa o desporto escolar e por cinco das associaçóes de modalidades federadas, as quais têm uma área geográfica de atuação para além do concelho de Évora. Neste grupo enquadram-se quatro clubes de modalidades federadas, uma fundação e um grupo de atividades de lazer.

Relativamente à percentagem de participação por género, $77 \%$ dos praticantes são do sexo masculino e $23 \%$ do feminino.

A FIGURA 2 permite constatar os dados estatísticos relativos à média, moda e mediana, das idades mínimas e máximas dos praticantes.

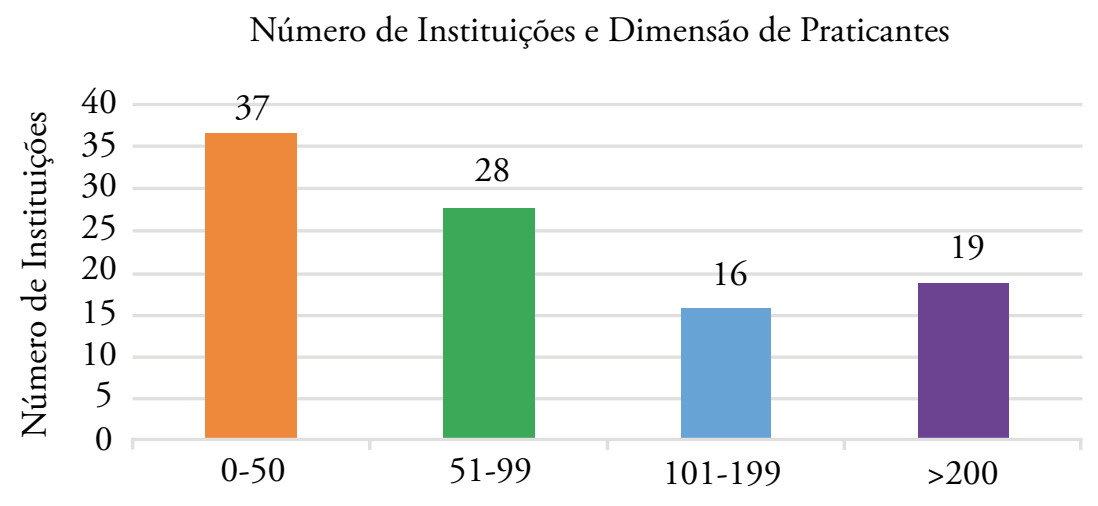

Número de praticantes

FIGURA 1 - Percentagem de instituições desportivas por número de praticantes.

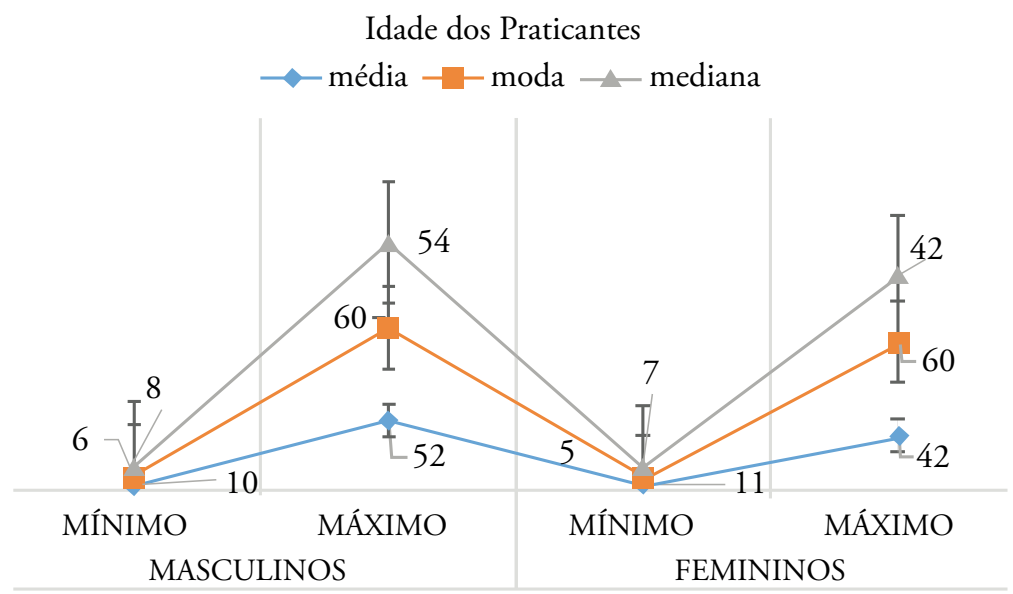

FIGURA 2 - Idade dos praticantes por sexo.

A análise estatística deste conjunto de dados revelou uma diferença de 10 anos, entre o sexo feminino e o sexo masculino relativamente à média das idades do praticante mais velho de cada instituição. Foram ainda encontradas diferenças significativas na mediana das idades máximas, onde homens e mulheres apresentam 54 e 42 anos, respetivamente.

Os resultados sobre o financiamento dividem-se em dois eixos, FIGURA 3.

Relativamente ao financiamento $36 \%$ das instituiçóes mencionaram que recorrem a financiamento externo à sua organização, enquanto $64 \%$ se apoiam maioritariamente no financiamento interno, ou seja, mais de dois terços das instituiçóes desportivas autofinanciam-se. Sendo que, 30\% revelaram que o financiamento conseguido permite desenvolver todos os projetos desejados, enquanto $70 \%$ afirmaram que o financiamento era insuficiente.

As FIGURAS 4 e 5 permitem observar as atividades mais disponibilizadas, pelas organizaçóes desportivas, para o sexo masculino e feminino. 
Natureza do Financiamento (\%)

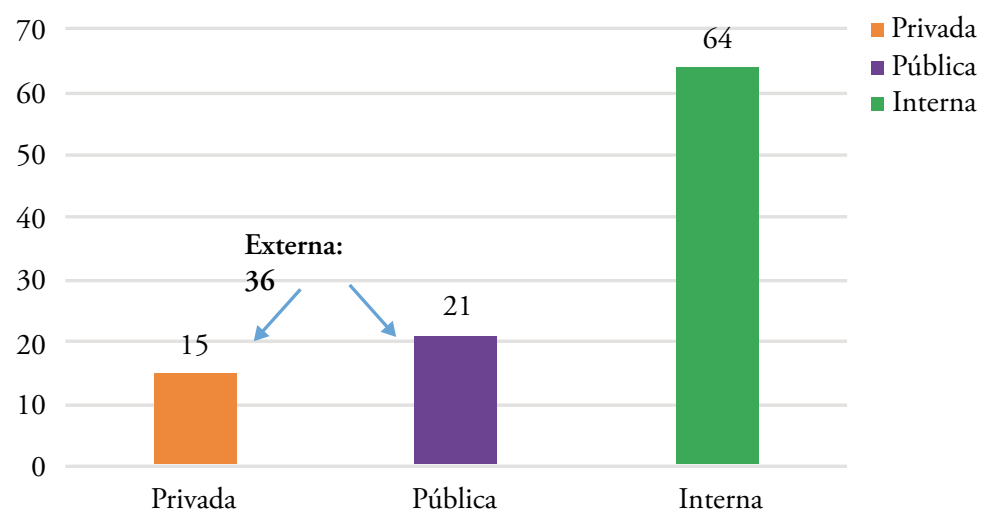

FIGURA 3 - Natureza do financiamento em percentagem.

Modalidades mais Oferecidas

a Praticantes do Sexo Masculino

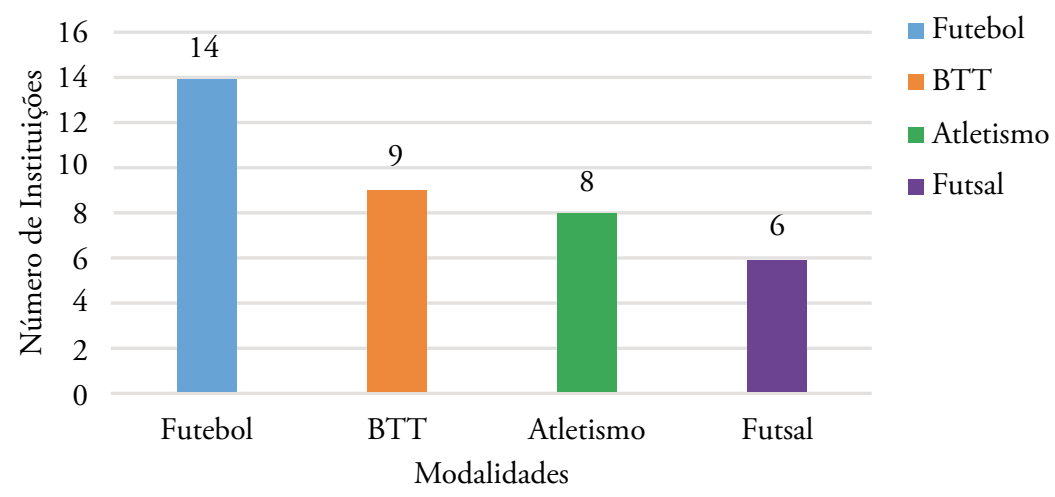

FIGURA 4 - Modalidades desportivas mais oferecidas a praticantes do sexo masculino.

Modalidades mais Oferecidas

a Praticantes do Sexo Feminino

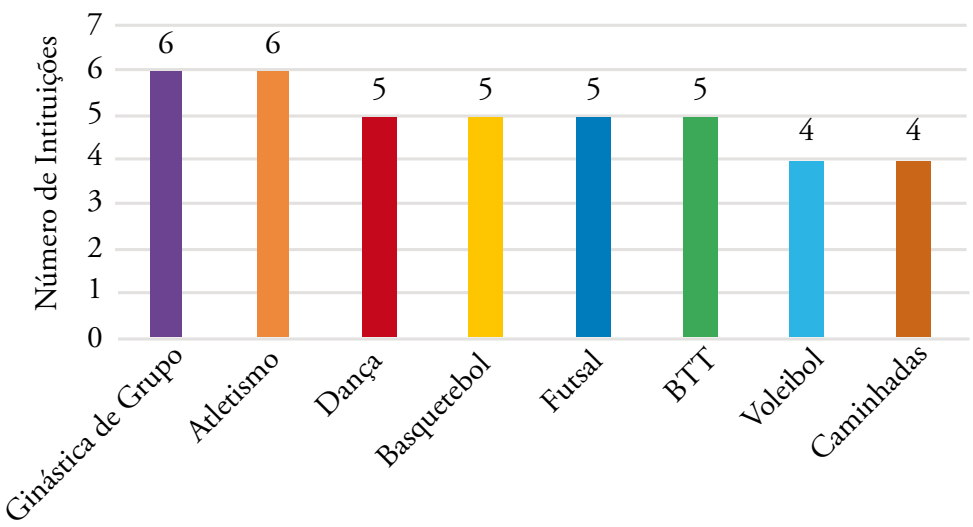

- Ginástica de Grupo

Atletismo

- Dança

$\square$ Basquetebol

Futsal

BTT

- Voleibol

- Caminhadas

Modalidades

FIGURA 5 - Modalidades desportivas mais oferecidas a praticantes do sexo feminino.

A atividade mais disponibilizada pelas instituições desportivas, para o género masculino, é o futebol
(14 instituiçóes), enquanto para o género feminino é o atletismo (6 instituiçóes). 


\section{Densidade}

A FIGURA 6 permite-nos visualizar as percentagens totais de densidade, registadas em cada rede.

$\mathrm{Da}$ análise efetuada às conexôes totais existentes nas redes de contactos formais, informais, partilha de recursos (materiais, físicos, humanos e financeiros) e rede de desenvolvimento desportivo, obteve-se uma densidade muito baixa. Como exceçáo aparece a rede de contactos futuros, que se situa neste estudo, nas redes de densidade baixa, facto que revela, globalmente, uma rede com nós soltos e com fluxos unidirecionais. A assimetria observada em todas as matrizes caracteriza-se por ausência de reciprocidade nos laços, ou seja, na maioria dos relacionamentos são relatados laços com a organização $\mathrm{A}$, contudo, a organização $A$ não relatou contacto com a organização $\mathrm{B}$ (vínculos não confirmados). Todavia, a matriz simétrica de dados assume a existência de relacionamento ${ }^{19}$.

Densidade das Redes Estudadas (\%)

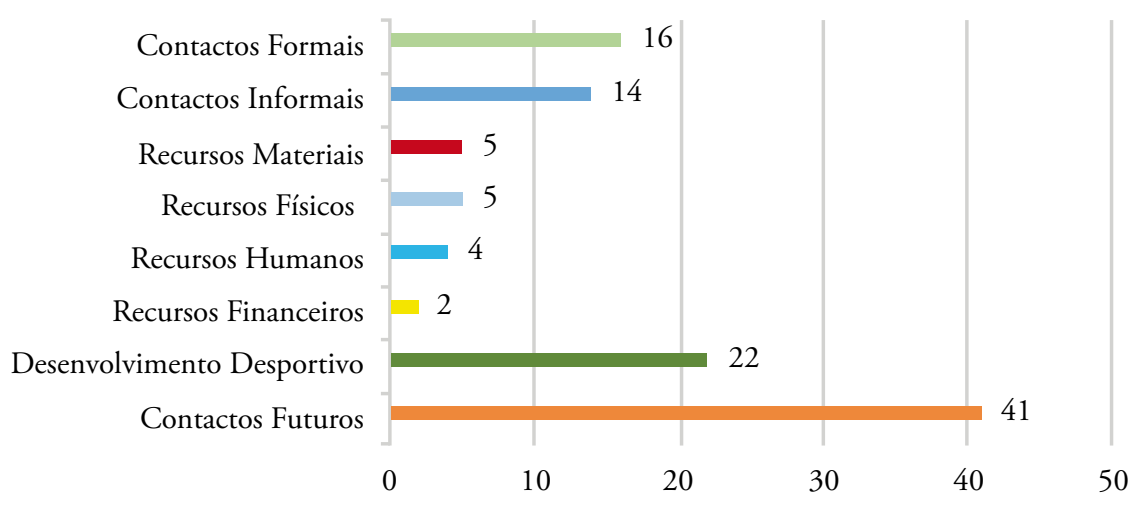

FIGURA 6 - Densidade das redes estudadas.

Ao comparar as percentagens de contactos das redes formais (16\%) e informais (14\%), verificase que estes se fazem, preferencialmente, por via formal. As percentagens são esclarecedoras do fraco relacionamento em rede, isto é, num quadro de 3.192 interaçóes possíveis em rede, apenas se verificam 525 nós na rede formal e 464 na rede informal.

A densidade média observada na partilha de recursos (materiais, físicos, humanos e financeiros) foi de $4 \%$. As relações de cooperação são efetuadas de forma mais significativa nos recursos materiais (5\%) e físicos (5\%), seguindo-se os recursos humanos (4\%). Relativamente aos recursos financeiros, a rede mostra quase inexistência de partilha nesta área (2\%).

A questão sobre quem contribui de forma mais efetiva para o desenvolvimento desportivo do concelho de Évora, foi realizada com um duplo sentido - conhecer quais as instituiçôes que recebem das demais o reconhecimento sobre o trabalho realizado em prol do desenvolvimento desportivo; perceber se as instituições desportivas, de forma geral, têm conhecimento das atividades que são desenvolvidas pelas outras instituiçóes desportivas. A rede obteve $22 \%$ de densidade, ou seja, dos 3.192 relacionamentos possíveis, apenas se verificaram 702. Da dimensão da matriz, identificase que muitas das instituiçóes desportivas não detêm, eventualmente, um conhecimento acerca dos projetos e realidades das demais, facto que pode levá-las a não estabelecerem opiniáo sobre a questão, o que, certamente, também influencia a presente rede de relacionamentos.

Para o futuro, existe a ideia de uma rede de relaçôes interorganizacionais com uma dimensão muito superior à que atualmente se verifica, tendo o valor de densidade (41\%) superado todas as redes.

\section{Centralidade}

A FIGURA 7 permite visualizar a rede de contactos formais, onde a CME (ID22) obteve o valor mais expressivo ao nível da centralidade de todas as redes em estudo.

Ao nível da centralidade, situamo-nos perante uma rede egocêntrica, isto é, a CME (ID22) assume um papel central, mostrando que é o ator com mais influência, comparativamente com os restantes, uma vez que detém o maior número de fluxos dentro da rede. 
Este resultado pode indicar que a CME é uma instituição aberta à comunidade, que tem a possibilidade de apoiar e acompanhar as organizaçóes desportivas de diferentes formas, o que é também visível pela percentagem de respostas em que é referida, no que diz respeito à partilha de recursos materiais.

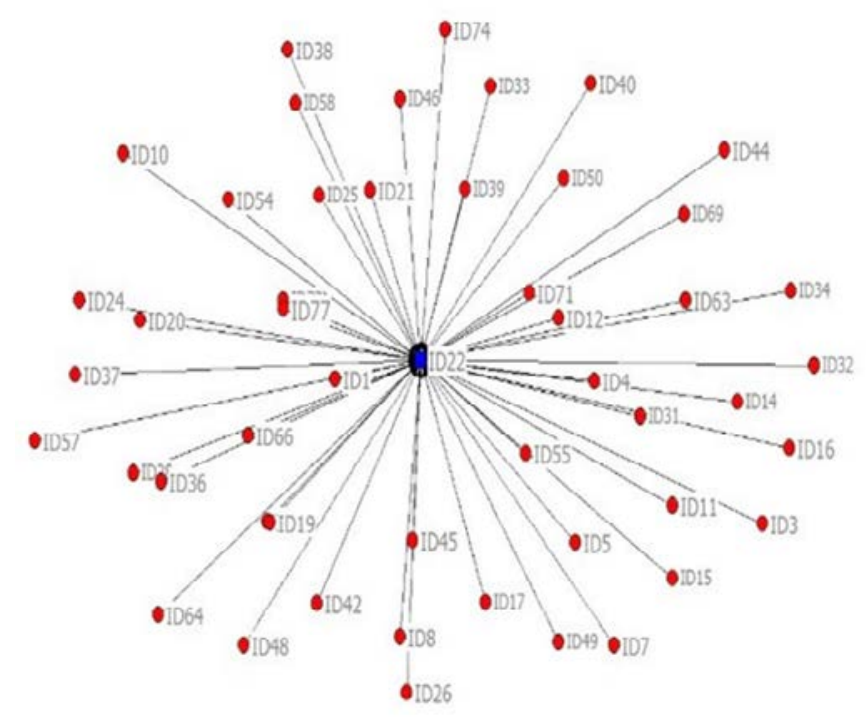

FIGURA 7 - Degree centrality: rede de contactos.

A restante rede apresenta sinais de uma liderança partilhada, ou seja, os relacionamentos em rede não apresentam sinais de interdependência. Vários estudos $^{24,20}$ encontraram uma relação positiva entre a liderança partilhada e o ambiente vivido em rede, o qual aumenta a eficácia e a satisfação coletiva.

\section{Nível de intermediaçáo}

A FIGURA 8 apresenta os valores individuais do grau de intermediação, das redes em estudo.

Relativamente aos valores, as redes situam-se entre $0,27 \%$ e $18 \%$, dados congruentes com a baixa densidade da rede global. A análise permite aferir que a informação disponível é essencialmente difundida pelos canais de comunicação formal, sendo que os contactos se estabelecem com a finalidade de informar, e/ou por motivaçóes e interesses específicos relacionados com as atividades desenvolvidas, orientando-se as conexóes entre os atores maioritariamente num sentido, ou seja, existem atores que estáo estrategicamente posicionados, sendo fundamentais na disseminação da informação, com maior evidência nas redes de contactos formais e informais.

Nível de Intermediação das Redes Estudadas

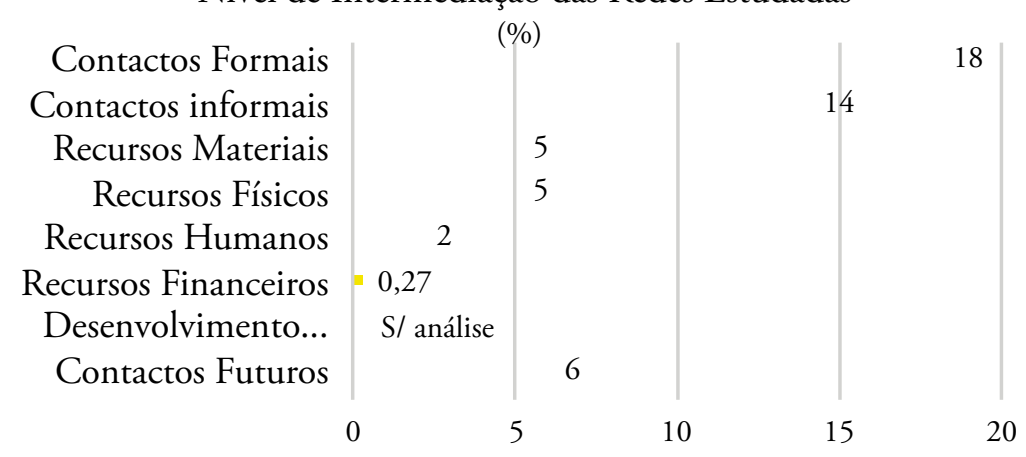

FIGURA 8 - Nível de intermediação das redes estudadas. 


\section{Subgrupos (cliques)}

A FIGURA 9 apresenta ao resultados da micro estrutura existente em rede.

Os resultados obtidos foram díspares, ou seja, nas análises efetuadas às matrizes adjacentes fica-se a conhecer que é através dos contactos futuros que existe possibilidade de maior coesão e participação em rede (101 subgrupos). Das restantes matrizes, o valor mais significativo encontra-se nos contactos formais (30 subgrupos).

O relacionamento interorganizacional das instituiçôes locais e grupos comunitários é fundamental, uma vez que incentiva os apoios públicos, facilita a gestáo, rentabiliza a oferta desportiva e aumenta a eficácia dos serviços a disponibilizar à comunidade ${ }^{18}$.

A pesquisa realizada por EDWARDs ${ }^{11}$ considera que o desporto tem sido utilizado para mobilizaçáo de participação social, estando o crescimento participativo associado ao aumento da vinculação entre organizações e comunidade. Desta forma, e perante os números de praticantes e modalidades disponibilizadas, podemos aferir que no concelho de Évora as organizaçóes desportivas desenvolvem, através das suas estruturas, uma função interventiva na comunidade.

Neste contexto é evidente que as organizaçōes desportivas do concelho de Évora, no presente momento, náo maximizam o seu potencial individual em proveito do coletivo, contudo, individualmente, desempenham um papel relevante na promoção desportiva, cumprindo a missão para a qual foram criadas. Importa ainda referir que o planeamento conjunto de projetos em áreas de sensibilidade social, como as atividades destinadas a jovens, adultos e idosos mais desprotegidos iria, certamente, dinamizar alguns recursos em parceria ${ }^{10}$.

Subgrupos das Redes Estudadas (\%)

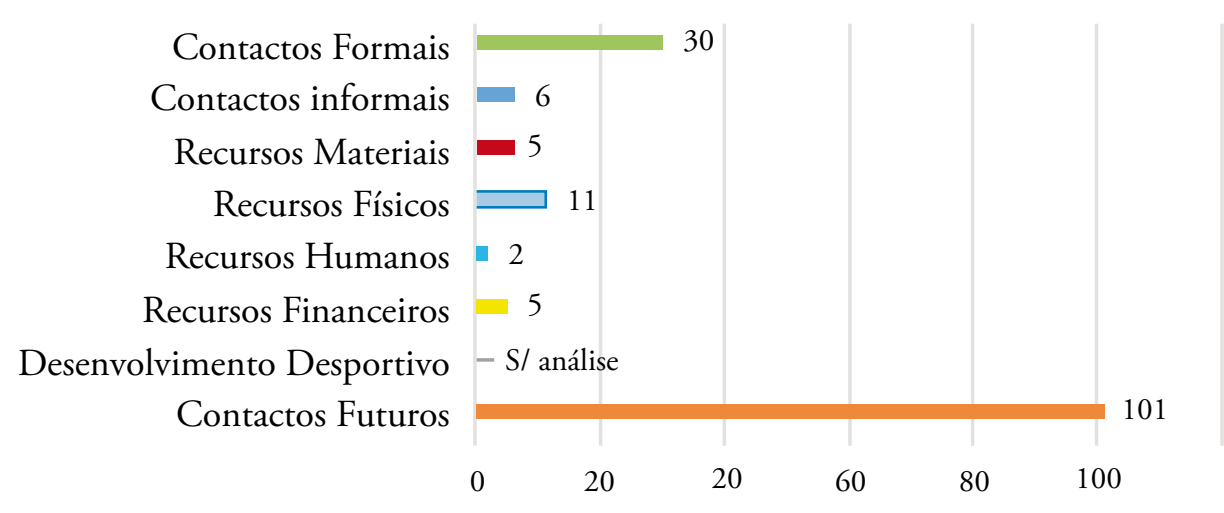

FIGURA 9 - Nível de coesão dos subgrupos.

A estrutura da rede de cooperação entre as organizaçóes promotoras de desporto do concelho de Évora, apresenta buracos estruturais com dimensão elevada, devido ao fraco relacionamento em rede.

Não encontramos dados que nos permitam dizer que existe uma hierarquia definida, no entanto, encontram-se vários atores chave nas redes de saída, enquanto nas redes de entrada prevalece o domínio da CME, pois grande parte das organizaçóes desportivas considera importante interagir com a Entidade Pública em diversos domínios, nomeadamente nos recursos materiais, humanos, físicos e financeiros.

Na sua generalidade as dinâmicas de cooperação são fracas, facto que terá influência na capacidade de gerar capital social no interior da rede. A motivaçáo para os contactos surge pela via da necessidade, fazendose essencialmente para troca de informação e através dos canais de comunicaçáo formais, facto que não tem em conta o posicionamento dos atores em rede.

Os atores demonstram uma intenção elevada de estabelecer contactos futuros, o que permite perspetivar dinâmicas participativas em rede com maior dimensão. A rede de cooperaçáo futura entre as instituiçóes desportivas do município de Évora, apresenta múltiplas potencialidades, as quais poderão resultar no acréscimo da partilha de recursos, no aumento de conhecimentos partilhados e da qualidade da oferta desportiva, e ainda na possibilidade de organização de eventos desportivos de interesse público, o que, naturalmente, contribuirá para o desenvolvimento desportivo do concelho. 
Por último, importa salientar a necessidade de alterar as frágeis dinâmicas de relacionamentos, incentivando açóes de cooperação interorganizacionais sistemáticas, com recurso a novos modelos de gestão e novas formas de participação em rede, que conduzam para um forte investimento das organizaçóes desportivas na comunidade.

\section{Abstract}

\section{Cooperation networks amongst a community's sports organizations}

It is highly important to understand the role sports organizations play as stakeholders in sports development in Portugal. Cooperation amongst sports institutions and organizations is key for the sector's sustainability and competitiveness. This study aims to identify the level of cooperation amongst sports organizations and sports institutions within Concelho de Évora and how that may lead to collective efficiency. Moreover, it aims at understanding how Évora's sports organizations and entities interact amongst each other. This exploratory study is indeed a case study. Social network analysis (SNA) was the primary tool for analyzing data. Data was gathered through a sociometric test and literature review. The results showed the existence of poor bonds of cooperation, with few exceptions within subgroups. Câmara Municipal de Évora is the network's most central element due to its elevated number of sports and affiliates. Furthermore the network's stakeholders are focused primarily on self-interests and contacts with others serve mainly the purpose of exchanging information. By improving the level of cooperation between organizations we could further improve sports within Évora's county.

KEYwORDS: Physical Activity and Community; Sports Sector; Social Network Analysis; Partnerships.

\section{Referências}

1. Girginov V. Culture and the study of sport management. Eur Sport Manag Q. 2010;10(4):397-417.

2. Vojinovic J, Maksimovic N, Kokovic D, Raic A, Matic R, Doder D. Predicting the future of sports organizations. Motriz. 2015;21(2):107-15.

3. Azevedo AMT. Análise institucional das organizaçóes desportivas: A intencionalidade desportiva das autarquias do distrito de Viseu [tese]. Vila Real (VR): Universidade de Trás-Os-Montes e Alto Douro; 2014.

4. Gómez-Gardeñes J, Reinares I, Arenas A, Floría LM. Evolution of cooperation in multiplex networks. Sci Rep. 2012;2(620):1-6.

5. Martínez BR. Entre la competencia y la cooperación: la construcción de redes entre las organizaciones no gubernamentales de desarrollo en Andalucía. Redes Rev Hisp Análisis Redes Soc. 2006;11(2):1-25.

6. Sanchez Herrera O, Duarte Martell RD. Historia en las redes, las redes de humanistas en el renacimiento. Redes Rev Hisp Análisis Redes Soc. 2015;26(2):70-83.

7. Faust V, Christens BD, Sparks SMA, Hilgendorf AE. Exploring relationships among organizational capacity, collaboration, and network change. Psychosoc Interv. 2015;24(3):125-31.

8. Pinto F. Gestão da execução da estratégia nas organizaçóes desportivas. In: Arraya M, Silva M, editores. Tendências contemporâneas da gestão desportiva. Lisboa: Visão e Contextos; 2014. p. 161-81.

9. Arco HMSLR. Tecendo redes: as relaçóes interorganizacionais de cooperação para a formação em Enfermagem [tese]. Évora (EV): Universidade de Évora, Departamento de Sociologia; 2010.

10. Evans SD, Rosen AD, Kesten SM, Moore W. Miami thrives: weaving a poverty reduction coalition. Am J Community Psychol. 2014;53(3-4):357-8.

11. Edwards MB. The role of sport in community capacity building: an examination of sport for development research and practice. Sport Manag Rev. 2015;18(1):6-19.

12. Berg BK, Warner S, Das BM. What about sport? A public health perspective on leisure-time physical activity. Sport Manag Rev. 2015;18(1):20-31. 
13. Babiak K. Determinants of interorganizational relationships: the case of a Canadian nonprofit sport organization. J Sport Manag. 2007;21(3):338-76.

14. Cruz JAW, Quandt Co, Kato HT, Martins TS. Cooperação e motivação em redes organizacionais: análise de configuracão estrutural de rede sociais em série histórica. Redes Rev Hisp Análisis Redes Soc. 2014;25(2):186-221.

15. Fialho JMR. Redes de cooperação interorganizacional: o caso das entidades formadoras do Alentejo Central [tese]. Évora (EV): Universidade de Évora, Departamento de Sociologia; 2007.

16. Balestrin A, Verschoore J. Redes de cooperação empresarial: estratégias de gestão na nova economia. Porto Alegre: Bookman; 2008.

17. Saragoça J. Governo electrónico local: diagnóstico sociológico, estratégia de actores e futuros possíveis para o distrito de Évora, Portugal [tese]. Évora (EV): Universidade de Évora, Departamento de Sociologia; 2011.

18. Sroka W, Cygler J. Pathologies in inter-organizational networks. Procedia Econ Financ. 2014;12:626-35.

19. Brand FC, Verschoore JR. A utilização de medidas de análise de redes sociais nas pesquisas em Administração. Rev Econ Gestão. 2014;14(35):212-37.

20. Menezes CRC, Olave MEL. Convergências teóricas: do processo de seleção natural à formação de redes interorganizacionais. Interfaces Cien Hum Soc. 2014;2(3):9-21.

21. Bachmann R, Witteloostuijn A. Analysing inter-organizational relationships in the context of their national business systems: a conceptual framework for comparative research. J Eur Soc. 2009;11(1):49-76.

22. Menger LM, Stallones L, Cross JE, Henry KL, Chen PY. Strengthening suicide prevention networks: interorganizational collaboration and tie strength. Psychosoc Interv. 2015;24(3):155-65.

23. Greenberg GA, Rosenheck RA. An evaluation of an initiative to improve coordination and service delivery of homeless services networks. J Behav Health Serv Res. 2010;37(2):184-96.

24. Maya-Jariego I, Holgado D. Editorial: network analysis for social and community interventions. Psychosoc Interv. 2015;24(3):121-4.

25. Silva CA, Fialho J, Saragoça J, coordenadores. Iniciação à análise de redes sociais: casos práticos e procedimentos com UCINET. Casal de Cambra: Caleidoscópio; 2013.

26. Silva CA, Fialho J, Saragoça J. Análise de redes sociais e sociologia da acção: pressupostos teórico-metodológicos. Rev Angolan Soc. 2013;11:91-106.

27. Gil AC. Métodos e técnicas de pesquisa social. 6a ed. São Paulo: Atlas; 2008.

28. Coutinho CP. Metodologia de investigação em ciências sociais e humanas: teoria e prática. 2a ed. Coimbra: Almedina; 2015.

29. Fortin MF. O processo de investigação: da concepção à realização. 5a ed. Loures: Lusodidacta; 2009.

\begin{tabular}{r|l} 
ENDEREÇO & \\
João António Garcia & Recebido para publicação: 12/o8/2017 \\
Rua Romão Ramalho, s/n & Aceito: 29/12/2017 \\
7000-671 - Évora - PORTUGAL & \\
e-mail: j.ahg@hotmail.com &
\end{tabular}

